Old Dominion University

ODU Digital Commons

Physics Faculty Publications

Physics

$12-2019$

Question 1: Electric Cars; Question 2: Chicken Poop

Larry Weinstein

Follow this and additional works at: https://digitalcommons.odu.edu/physics_fac_pubs

Part of the Physics Commons 


\section{Question 1: Electric cars; Question 2: Chicken poop}

Larry Weinstein

Citation: The Physics Teacher 57, 653 (2019); doi: 10.1119/1.5135807

View online: https://doi.org/10.1119/1.5135807

View Table of Contents: https://aapt.scitation.org/toc/pte/57/9

Published by the American Association of Physics Teachers

\section{ARTICLES YOU MAY BE INTERESTED IN}

Solutions for Fermi Questions, December 2019: Question 1: Electric cars; Question 2: Chicken poop The Physics Teacher 57, A653 (2019); https://doi.org/10.1119/1.5135779

That's the way the ball bounces

The Physics Teacher 57, 639 (2019); https://doi.org/10.1119/1.5135799

Two Looks at the Periodic Table

The Physics Teacher 57, 616 (2019); https://doi.org/10.1119/1.5135791

Electric Circuits as Seen by Thermal Imaging Cameras

The Physics Teacher 57, 597 (2019); https://doi.org/10.1119/1.5135785

Figuring Physics November 2019 Solution

The Physics Teacher 57, 651 (2019); https://doi.org/10.1119/1.5135805

Solution to the September, 2019 Challenge Know your ABC's, Take 2.

The Physics Teacher 57, A639 (2019); https://doi.org/10.1119/1.5135778

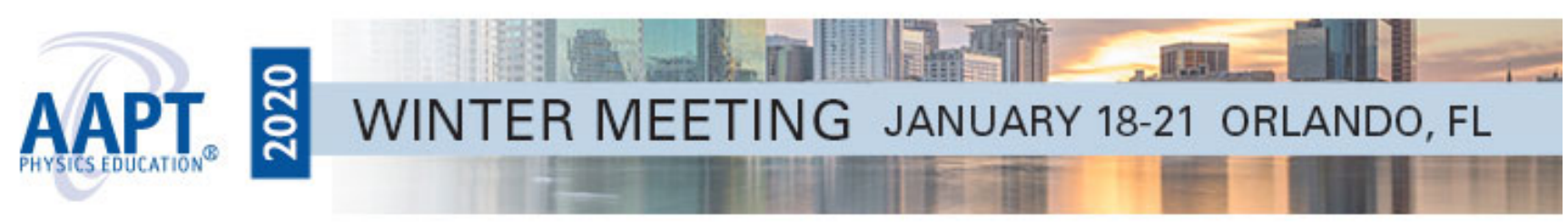




\section{Data Chart}

\begin{tabular}{|c|c|c|}
\hline \multicolumn{1}{|c|}{ Conductor } & Current & Voltage +/- 1V \\
\hline None (open) & 0 & $5 \mathrm{~V}$ \\
\hline Wire (shorted) & $220 \mathrm{~mA}$ & $1 \mathrm{~V}$ \\
\hline 100 ohms & $30 \mathrm{~mA}$ & $3 \mathrm{~V}$ \\
\hline One hand - limp & $2 \mu \mathrm{A}$ & $4 \mathrm{~V}$ \\
\hline One hand - tight & $5 \mu \mathrm{A}$ & $4 \mathrm{~V}$ \\
\hline One hand - wet & $40 \mu \mathrm{A}$ & $4 \mathrm{~V}$ \\
\hline Both hands & Similar results & Similar results \\
\hline
\end{tabular}

\section{Used against a plasma globe and $E=h f$ for diodes demonstration}

It is interesting to note that a plasma globe will activate the Energy Stick (Fig. 4). This will work in either direction because plasma globes supply an alternating voltage. Inside of the Energy Stick are three diodes_red, green, and blue. As the Energy Stick is brought near the plasma globe, these will turn on one at a time. The red one first, then the green, followed very closely by the blue. This demonstrates that more voltage or energy is required to create red light than blue light. This is a lesson in modern physics and consistent with

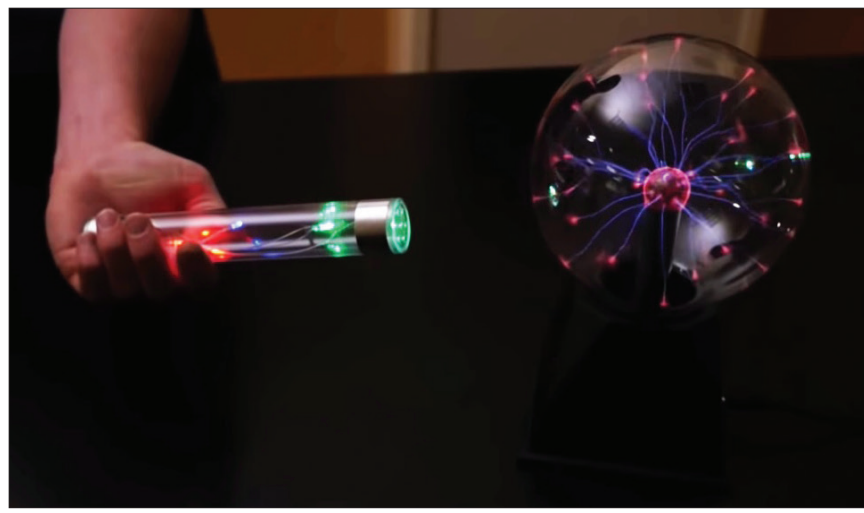

Fig 4. The plasma globe can substitute as a partner's hand, completing the circuit, not with a conducting path, but with an electric field filling space. Bring the stick slowly toward the globe and predict which diode will turn on first.

the Planck-Einstein photon energy formula $E=h f$. (It is also possible to get this same demonstration with no plasma globe by simply gently touching the metal, but this is hard to do.) While you have the plasma globe out, it also can be shown that the electric field is radial by turning the Energy Stick; it will turn off unless aligned with the field (at some positions).

\section{Reference}

1. Thanks to Lisa Taylor for this demo.

\section{Fermi Questions}

\section{- Question 1: Electric cars}

How much more electrical energy will the United States need to generate if everyone drives electric cars?

\section{Larry Weinstein, Column Editor} Old Dominion University, Norfolk, VA 23529; weinstein@odu.edu

\section{- Question 2: Chicken poop}

How much chicken excrement is produced in the United States every year?

Look for the answers online at tpt.aapt.org under "Browse," at the very end of the current issue.

Question suggestions are always welcome!

For more Fermi questions and answers, see Guesstimation 2.0: Solving Today's Problems on the Back of a Napkin, by Lawrence Weinstein (Princeton University Press, 2012). 